\title{
The influence of water jet diameter and bone structural properties on the efficiency of pure water jet drilling in porcine bone
}

\author{
S. den Dunnen ${ }^{1}$ and G. J. M. Tuijthof ${ }^{1,2}$ \\ ${ }^{1}$ Delft University of Technology, Dept. of Biomechanical Engineering, Delft, the Netherlands \\ ${ }^{2}$ Academic Medical Center, Dept. Orthopedic Surgery, Amsterdam, the Netherlands \\ Correspondence to: S. den Dunnen (s.dendunnen@tudelft.nl)
}

Received: 28 April 2014 - Revised: 16 July 2014 - Accepted: 14 August 2014 - Published: 5 September 2014

\begin{abstract}
Using water jets in orthopedic surgery to drill holes in bones can be beneficial due to the absence of thermal damage and the always sharp cut. To minimize operating time and the volume of water that is used, the efficiency (volume of removed bone per added volume of water) of the water jet should be maximized. The goal was to study the effect of the open trabecular bone structure on the efficiency for different water jet diameters. 86 holes were drilled in porcine tali and femora submerged in water with nozzles of $0.3,0.4,0.5$ and $0.6 \mathrm{~mm}$ at $70 \mathrm{MPa}$ during $5 \mathrm{~s}$ and a standoff distance of $8 \mathrm{~mm}$. MicroCT scans were made to measure the removed bone volume and the bone structural properties Trabecular Spacing (Tb.Sp.), Trabecular Thickness (Tb.Sp.) and Bone Volume Fraction (BV/TV). Pearson's correlation tests $(p<0.05,95 \%$ confidence interval) were performed for each water jet diameter using the bone structural property as an independent factor and the efficiency as a dependent factor. No significant differences were found between the nozzle diameters in the material removal rates per added volume of water. The efficiency decreased for an increase in Tb.Th. and BV/TV for nozzles of $0.3,0.4$ and $0.5 \mathrm{~mm}$. The $0.6 \mathrm{~mm}$ nozzle showed less influence of the Tb.Th. and BV/TV. The Tb.Sp. has no influence on the efficiency of a water jet.

The total volume of added water combined with the Tb.Th. or BV/TV is a leading measure for the volume of bone material that is removed, which provides freedom in the development of water jet instruments as the nozzle diameter, pressure and jet time can be chosen in accordance to the maximum operating time requirements or dimensional limitations of a design.
\end{abstract}

\section{Introduction}

Water jet technology can provide a valuable contribution for drilling of bone in orthopedic surgery due to its potential advantages over existing bone cutting or drilling instruments. Conventional drill bits used for bone drilling increase the temperature of the surrounding bone tissue (Eriksson et al., 1984a; Matthews and Hirsch, 1972), which can lead to unwanted cell damage or cell death, causing poor bone healing (Eriksson and Albrektsson, 1984; Eriksson et al., 1984b; Iyer et al., 1997). Using water jets to machine bone barely increases the temperature of the surrounding tissue (Schmolke et al., 2004), causing no thermal damage to the cells. Besides the thermal advantage, the cut of a water jet is always sharp and clean due to the absence of contact between the tissue and the water jet instrument.

The water volume flow during surgery should be minimized to allow the irrigation system to remove the superfluous water when water jetting. Commercially available irrigation systems such as the HydroFlex AD (Davol, Warwick, RI, USA) are able to pump out up to $2500 \mathrm{~mL} \mathrm{~min}^{-1}$. This is equivalent to the flow rate of a nozzle diameter of $0.37 \mathrm{~mm}$ at $70 \mathrm{MPa}$. When the volume flow of the water jet instrument exceeds the maximum capacity of the irrigation pump, only a small amount of water can be temporarily stored in the tight spaces of the intra-acrticular joint before an uncontrolled outflow occurs and superfluous extravasation into the surrounding caspule takes place. To decrease the volume flow 


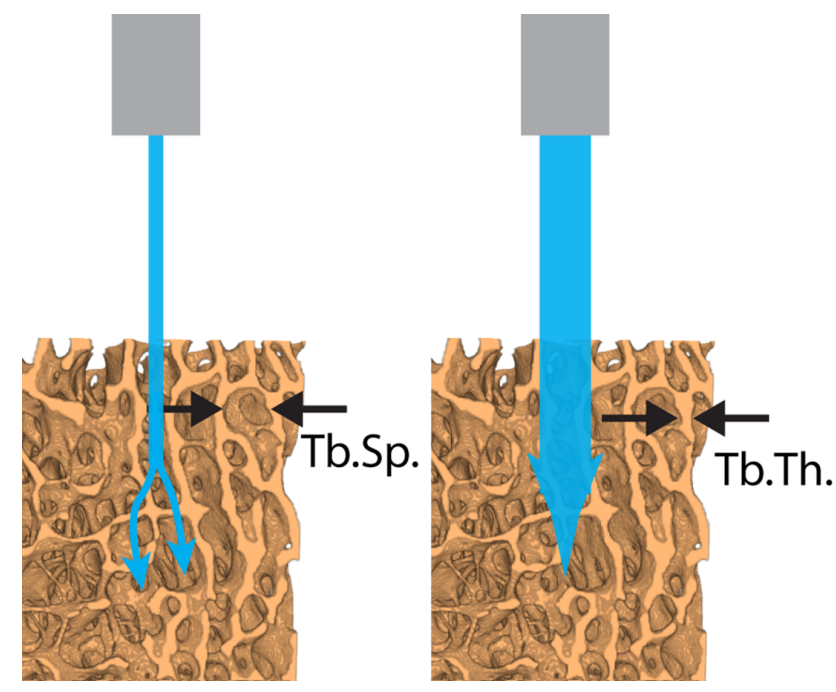

Figure 1. The potential cause for a change in efficiency of a water jets with a smaller diameter than the Tb.Th. or Tb.Sp. The water takes the path of the least resistance in the spacing between the trabeculae without breaking the struts.

of a water jet, intermittent water jetting can be performed or a smaller water jet diameter can be chosen. The latter can influence the efficiency of the water jet, which is the removed volume of (bone) material per added volume of water. The efficiency can be influenced as follows. Bone consists of a characteristic open structure of trabeculae with a certain thickness (Tb.Th.), spacing (Tb.Sp.) and density (BV/TV) (Hildebrand et al., 1999) (Fig. 1). Water jets having a smaller diameter than the Tb.Sp. can pass through the cavities of the bone without removing the bone itself, and trabecular struts with a larger $\mathrm{Tb}$.Th. than the water jet diameter might not break (Fig. 1). These aspects can result in a decreased efficiency for water jet diameters with a smaller diameter than the Tb.Sp. or Tb.Th. In that case, increased jet times and as a result larger water volumes are required to remove the same quantity of bone tissue. For application in surgery, this would imply an increased operating time or an increased total volume of added water.

This study investigates the efficiency of water jets with various diameters for drilling in bone tissue by comparing the bone tissue removal rates per added volume of water. To investigate whether the bone tissue structure affects the efficiency, the BV/TV, Tb.Th. en Tb.Sp. are analyzed. The results of this study can be used for future design of orthopedic water jets instruments by providing the optimal water jet diameter for minimizing the total volume of added water or operating time.

\section{Materials and methods}

The volume of water and its velocity provide a good indication of the effectiveness of a water jet when machining homogeneous materials (Summers, 1995). The velocity of a water jet $v_{\text {liquid }}\left(\mathrm{m} \mathrm{s}^{-1}\right)$ can be determined by a simplification of Bernoulli's equation:

$v_{\text {liquid }}=\sqrt{\frac{2 P}{\rho}}$

in which $P$ is the water pressure $\left(\mathrm{N} \mathrm{m}^{-2}\right)$ and $\rho$ is the fluid density $\left(\mathrm{kg} \mathrm{m}^{-3}\right)$. The volume of water $V_{\text {water }}\left(\mathrm{m}^{3}\right)$ can be determined by Equation (2):

$V_{\text {water }}=\frac{1}{4} \pi \cdot D^{2} \cdot v_{\text {liquid }} \cdot t$

in which $D(\mathrm{~m})$ is the water jet diameter and $t(\mathrm{~s})$ is the jet time.

Using a traditional dimensionless energy equation to describe the efficiency has limited value, since a percentage cannot be used for determining the water jet machine settings to remove a predetermined volume of bone. Instead, the measure to describe the efficiency is defined as the volume of removed bone tissue per added volume of water VRR $\left(\mathrm{mm}^{3} \mathrm{~L}^{-1}\right)$ in accordance to:

$\mathrm{VRR}=\frac{V_{\text {rembonetissue }}}{1000 \cdot V_{\text {water }}}=\frac{V_{\text {rembonetissue }}}{250 \cdot \pi \cdot D^{2} \cdot \sqrt{\frac{2 P}{\rho}} \cdot t}$

in which $V_{\text {rembonetissue }}\left(\mathrm{mm}^{3}\right)$ is the volume of removed bone tissue. Using the VRR shows how much water is required to machine a certain volume of bone tissue, allowing Eqs. (1) and (2) to be used for determining $P, D$ and $t$.

To investigate the influence of the trabecular structures on the water jet efficiency of various water jet diameters, nozzle diameters were chosen that were smaller than, larger than or equal to the mean Tb.Th. $(0.5 \mathrm{~mm})$ and Tb.Sp. $(0.3 \mathrm{~mm})$ found in porcine bone specimens (den Dunnen et al., 2013b). This resulted in the following nozzle diameters that were tested: $0.3,0.4,0.5$ and $0.6 \mathrm{~mm}$. The experiment layout is summarized in Table 1.

Water jet drilling of bony tissue was performed with a custom-made setup that used a MTS model 311.21 tensile tester (HTS, Eden Prairie, Minnesota, Unites States of America) to compress a water filled cylinder (Holmatro HAC30S15, Glen Burnie, Maryland, USA) with a force of $295 \mathrm{kN}$, resulting in a water pressure of $70 \mathrm{MPa}$ at the nozzle (den Dunnen et al., 2013b). Via a hose the cylinder was connected to a holder that allowed nozzles with various diameters to be connected.

Ten fresh porcine tali and ten femoral condyles (34 months, approximately $40 \mathrm{~kg}$ ) obtained from an animal experiment were used. The distance between the specimen and the nozzle (stand-off distance) was $8 \mathrm{~mm}$ and the jet time $5 \mathrm{~s}$. During the experiment, both the nozzle and the specimen were situated underwater to mimic arthroscopic surgery. 86 holes were drilled in a random order of sequence perpendicularly in the articular surface of the tali and femora: 13,26 , 
Table 1. The experiment variables and factors.

\begin{tabular}{llcccc}
\hline & Nozzle diameter $(\mathrm{mm})$ & 0.3 & 0.4 & 0.5 & 0.6 \\
\hline Independent variable & Bone structural properties & BV/TV & Tb.Th. & Tb.Sp. \\
\hline Dependent variable & Water jet efficiency & VRR & & & \\
\hline
\end{tabular}

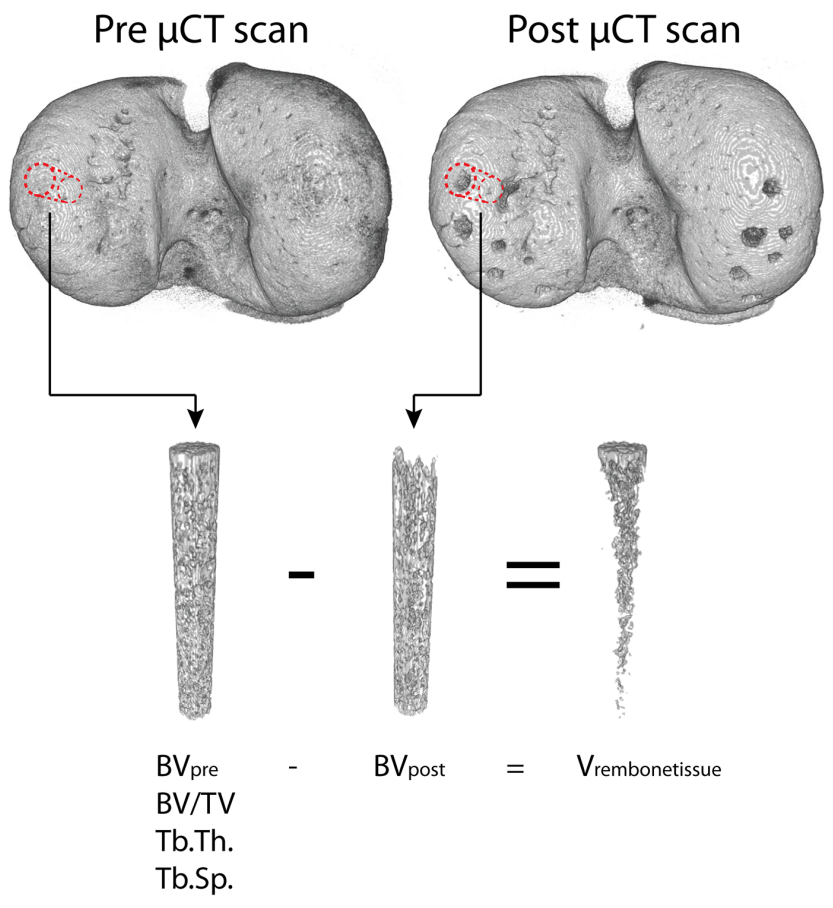

Figure 2. Method of measuring the bone structural properties and bone volumes.

26 and 22 holes with nozzle diameters of $0.3,0.4,0.5$ and $0.6 \mathrm{~mm}$, respectively.

Pre- and post-experimental microCT scans of each bone specimen were used to measure the BV/TV, Tb.Th., Tb.Sp. and $V_{\text {bonetissue }}$ by using a Scanco microCT80 scanner (Scanco Medical AG, Brüttisellen, Switzerland) at a spatial resolution of 37 micron. The scans were registered using Amira version 5.3.3 (Visualization Sciences Group, Burlington, Miami, USA). Regions of interest of each drilled hole were identified in the post-experimental scan and copied to the pre-experimental scan using ImageJ version $1.46 \mathrm{~m}$. Segmentations were made from the regions of interest. After applying a global threshold to the segmentations, the mean BV/TV, Tb.Th., Tb.Sp. and the total bone volume of the segmentation $\left(\mathrm{BV}_{\text {pre }}\right)$ were determined in the pre-experimental scan. In the segmentation of the post-scan, the total bone volume was measured $\left(\mathrm{BV}_{\text {post }}\right)$. $V_{\text {rembonetissue }}$ was determined by subtracting $B V_{\text {post }}$ from $B V_{\text {pre }}$ (Fig. 2).

To determine whether there is a difference in efficiency between the nozzles, Pearson's correlation tests are performed

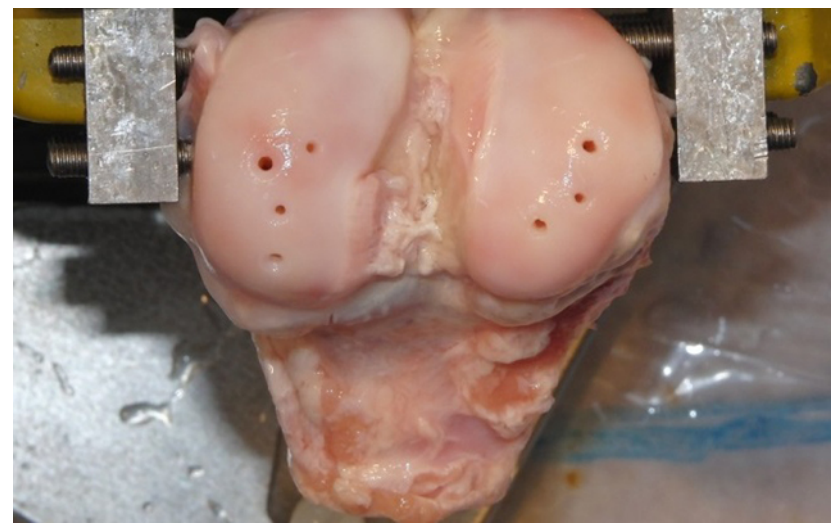

Figure 3. Drilled holes in porcine femora using water jets with various nozzle diameters.

Table 2. Statistical outcomes of the experiment of the VRR by different nozzle diameters. $R^{2}$ : coefficient of determination. $p$ : significance of the regression analysis.

\begin{tabular}{lrrrrr}
\hline & \multicolumn{2}{c}{ BV/TV } & \multicolumn{2}{c}{ Tb.Th. } & Tb.Sp. \\
\hline Nozzle & $R^{2}$ & $p$ & $R^{2}$ & $p$ & $p$ \\
\hline $0.3 \mathrm{~mm}$ & 0.47 & 0.01 & 0.51 & 0.01 & 0.78 \\
$0.4 \mathrm{~mm}$ & 0.64 & $<0.001$ & 0.55 & $<0.001$ & 0.35 \\
$0.5 \mathrm{~mm}$ & 0.57 & $<0.001$ & 0.55 & $<0.001$ & 0.80 \\
$0.6 \mathrm{~mm}$ & 0.17 & 0.05 & 0.19 & 0.04 & 0.45 \\
\hline All nozzles & 0.47 & $<0.001$ & 0.36 & $<0.001$ & 0.64 \\
\hline
\end{tabular}

for each water jet diameter using the bone structural property as an independent factor and the VRR as a dependent factor. If no difference in efficiency is found, the same test is used to create a model that predicts the removed bone tissue for a given bone structural property. The tests were performed in IBM SPSS Statistics version 20 (Armok, New York, USA) with a confidence interval of $95 \%(a=0.05)$.

This study is a continuation of a published experiment that determined a correlation between the drilling depth, nozzle diameter and bone structural properties (den Dunnen et al., 2013b) and has therefore overlap regarding the actual performed experiment. The data presented in this article is new. 


\section{Results}

All water jet diameters resulted in holes in bone tissue (Fig. 3). Significant predictive models were determined to calculate the VRR for each nozzle diameter when using the BV/TV or Tb.Th. as a dependent factor (Table 2 and Fig. 4). The area covered by the $95 \%$ confidence interval overlapped for all nozzles. For the $0.6 \mathrm{~mm}$ nozzle model, the significance and $R^{2}$ was lower and the slope less steep than for the other three nozzle diameters (Table 2). No significant models where found using the Tb.Sp. as a predictor.

A linear regression analysis with the BV/TV, Tb.Th. or Tb.Sp. combined with the added volume of water as predictors showed the following three significant models to calculate the removed bone tissue:

$$
\begin{gathered}
V_{\text {rembonetissue }}=18.4 \cdot V_{\text {water }}-8.4 \cdot \frac{\mathrm{BV}}{\mathrm{TV}}+3.3 \\
\left(p<0.001, R^{2}=0.78\right) \\
V_{\text {rembonetissue }}=20.4 \cdot V_{\text {water }}-20.4 \cdot \mathrm{Tb} . \mathrm{Th} .+2.6 \\
\left(p=0.001, R^{2}=0.77\right) \\
V_{\text {rembonetissue }}=16.5 \cdot V_{\text {water }}+16.6 \cdot \mathrm{Tb} . \mathrm{Sp} .-4.4 \\
\left(p<0.001, R^{2}=0.70\right)
\end{gathered}
$$

\section{Discussion}

No evidence was found that the nozzle diameter affects the efficiency when water jet drilling in bone tissue. The individual measurements as well as the predictive models overlap for all nozzle diameters (Fig. 4). Hence, the VRR and thus the efficiency is not influenced by the nozzle diameter. Consequently, the total volume of added water appears to be a leading factor for the drilling capacity. For nozzles smaller than $0.6 \mathrm{~mm}$, a clear decline in VRR is present for an increase in BV/TV or Tb.Th. An explanation for this trend can be that the BV/TV and the Tb.Th. determine to a large extend the mechanical properties of the bone (Day, 2005). A higher $\mathrm{BV} / \mathrm{TV}$ or $\mathrm{Tb}$.Th. results in an increased maximum tensile strength, compressive strength and modulus of elasticity of the tissue (Cory et al., 2010; Nazarian et al., 2011). The increased strength has a negative effect on the machinability of bone with pure water jets (Tikhomirov et al., 1992). Thus, it is not the efficiency of the water jet that changes, but the mechanical properties of the material that is drilled in, which makes the removal of the bone more difficult.

Regardless the overlap, the $0.6 \mathrm{~mm}$ nozzle seems to be less affected by the Tb.Th. and BV/TV than the other nozzles. An explanation of this can be that the width of the water jet exceeds the average width of a trabecular strut, which was $0.48 \mathrm{~mm}$ in the experiment. This causes the water jet to fully enclose the strut in its devastating stream of water, washing it away entirely instead of nibbling bone material away at the sides of the strut, which is the case for smaller nozzle diameters.

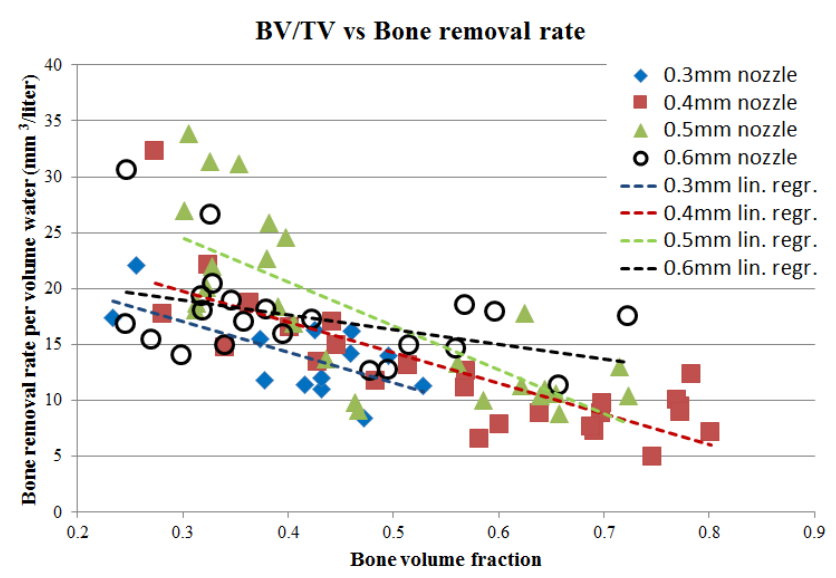

Tb.Th. vs Bone removal rate

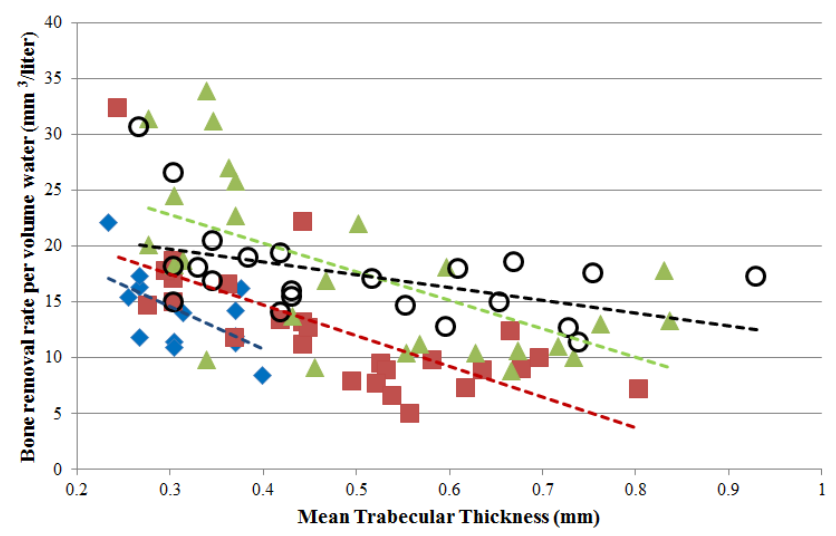

Tb.Sp. vs Bone removal rate

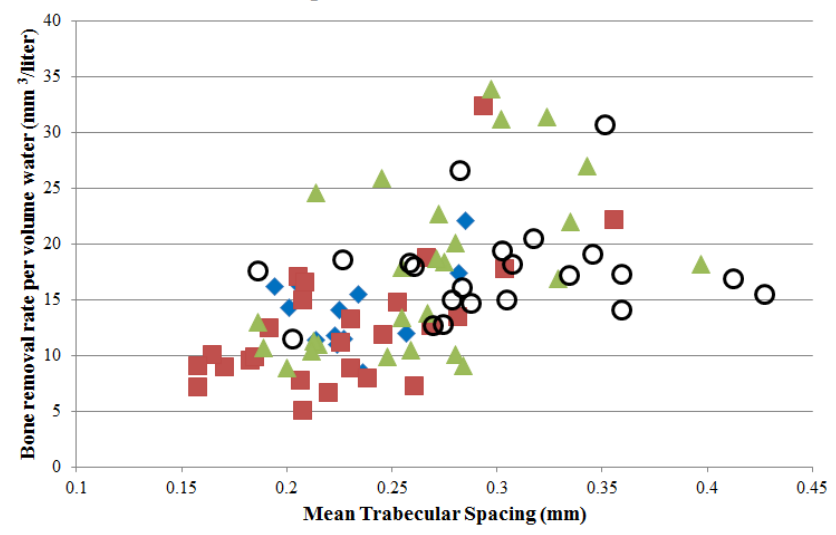

Figure 4. The influence of the nozzle diameter, BV/TV, Tb.Th. and Tb.Sp. on the VRR. The dashed lines represent the outcomes of linear regression analyses for the individual nozzle diameters. The overlap in VRR and regression trend lines indicate an absence of influence of the nozzle diameter on the VRR. No trend lines were depicted in the Tb.Sp. graph due to the lack of significance of the regression analysis for the individual nozzle diameters (Table 2). 
The experiment supports previous research (Summers, 1995; Tikhomirov et al., 1992; Hashish and Duplessis, 1978) that the velocity (Eq. 1) and the volume of water (Eq. 2) that is directed towards an object is leading for the total volume of material removal. By keeping $V_{\text {water }}$ constant, $D, t$ and $P$ can be chosen arbitrarily to remove a certain volume of material. However, the results cannot be extrapolated for all machine settings. Especially extreme low or high settings of $D, t$ and $P$ the model will be inaccurate. Equation (2) suggests a linear influence of jet time $(t)$ on the material removal. Previous studies showed that the drilling depth increase is maximum after initiating the water jet (Akkurt, 2009; Bach et al., 2007; Orbanic and Junkar, 2004; Pandey and Panda, 2013; Matthujak et al., 2013), and, after the first few tenths of a second, increases almost linearly until a maximum depth is reached. The linear phase is therefore limited to a specific range of $t$. The same holds for $P$ and $D$ in their respective ranges. For $P$, a minimal threshold needs to be met before bone material is removed, which lies between 30 and $45 \mathrm{MPa}$ depending on the bone tissue and $D$ (Honl et al., 2000a, b; den Dunnen et al., 2013a). The pressure range in which the pressure can be considered to have a linear influence is up to $120 \mathrm{MPa}$ (Mohamed, 2004; Orbanic and Junkar, 2004). Thus, the volume of and velocity of the water is a good measure for the total volume of material removal, but only when no extreme values for $D, t$ and $P$ are used to achieve this volume and velocity of the water.

Limiting factors could have influenced the results. In the experiment, the VRR was used to normalize for the differences in $V_{\text {water }}$ that is caused by differences in nozzle diameter. Keeping $V_{\text {water }}$ constant by adjusting $t$ (Eq. 2) might have resulted in different outcomes, as no compensation per unit volume of water would have been required. A drawback of adjusting $t$ would have been the increased influence of the attack time, which is the time required to build up the water pressure. In this experiment, the attack time was $0.3 \mathrm{~s}$, which consistently increased the jet time by $6 \%$ for all holes that were drilled. When various jet times would have been used, the influence of the attack time would not have been constant. Therefore, the results were normalized using the VRR instead of adjusting $t$.

The predictive models (Eqs. 4, 5 and 6) can be used for procedures where a predetermined volume of bone material needs to be removed, such as osteotomies and bone tumor removal. For these procedures, using the BV/TV to predict the volume of removed material (Eq. 4) is favorable since the $\mathrm{BT} / \mathrm{TV}$ can be measured in conventional CT scanners that are available in hospitals. Additionally, the BV/TV model provides the highest accuracy of the three equations. Using Eqs. (1) and (2), $P$ and $D$ can be determined for a given $t$. For time critical surgery, a low $t$ can be chosen. For delicate procedures that require increased precision, a high $t$ can be used, causing $P$ and $D$ to be lower providing the surgeon more control by the slow bone removal process.

\section{Conclusions}

For the development of surgical instruments for bone surgery that rely on water jet technology, a water jet diameter can be chosen in accordance to the specific requirements of the surgical procedure without affecting the total volume of water that is required to remove the specific volume of bone tissue. If an irrigation system is required for the removal of superfluous water, a smaller nozzle is advised to stay within the limits of the maximum capacity of the pump. For $70 \mathrm{MPa}$, this would mean a nozzle diameter smaller than $0.37 \mathrm{~mm}$. For developments in minimally invasive surgery where the space in a joint is limited, the instrument should be equipped with a small nozzle, which allows thinner tubing but leads to an increased jet time. For time critical surgery, a larger nozzle is advised.

The total volume of added water combined with the Tb.Th., BV/TV or Tb.Sp. is a leading measure for the volume of bone material that is removed, which can be described by linear models described in this paper. The models can be used to determine the water jet machine settings for procedures where a predetermined volume of bone material needs to be removed, such as osteotomies and bone tumor removal.

Edited by: J. van den Dobbelsteen

Reviewed by: S. Hloch and J. Foldyna

\section{References}

Akkurt, A.: The effect of material type and plate thickness on drilling time of abrasive water jet drilling process, Mater Design, 30, 810-815, doi:10.1016/j.matdes.2008.05.049, 2009.

Bach, F.-W., Biskup, C., Kremer, G., and Schmolke, S.: Investigation of the AWIJ-Drilling Process in Cortical Bone, Proceedings of the 2007 American WJTA Conference and Expo, Houston, USA, 1-D, 2007.

Cory, E., Nazarian, A., Entezari, V., Vartanians, V., Muller, R., and Snyder, B. D.: Compressive axial mechanical properties of rat bone as functions of bone volume fraction, apparent density and micro-ct based mineral density, J. Biomechan., 43, 953-960, doi:10.1016/j.jbiomech.2009.10.047, 2010.

Day, J. S.: Bone Quality: The Mechanical Effects of Microarchitecture and matrix properties, Optima Grafische Publicatie, Rotterdam, 2005.

den Dunnen, S., Kraaij, G., Biskup, C., Kerkhoffs, G. M. M. J., and Tuijthof, G. J. M.: Pure waterjet drilling of articular bone: an in vitro feasibility study, J. Mech. Eng. - Strojniski Vestnik, 59, 425-432, 2013a.

den Dunnen, S., Mulder, L., Kerkhoffs, G. M. M. J., Dankelman, J., and Tuijthof, G. J. M.: Waterjet drilling in porcine bone: The effect of the nozzle diameter and bone architecture on the hole dimensions, J. Mechan. Behavior Biomed. Materials, 27, 84-93, doi:10.1016/j.jmbbm.2013.06.012, 2013b. 
Eriksson, R. A. and Albrektsson, T.: The effect of heat on bone regeneration: an experimental study in the rabbit using the bone growth chamber, J. Oral Maxillofac. Surgery: official journal of the American Association of Oral and Maxillofacial Surgeons, 42, 705-711, 1984.

Eriksson, A. R., Albrektsson, T., and Albrektsson, B.: Heat caused by drilling cortical bone. Temperature measured in vivo in patients and animals, Acta Orthop Scand, 55, 629-631, 1984a.

Eriksson, R. A., Albrektsson, T., and Magnusson, B.: Assessment of bone viability after heat trauma. A histological, histochemical and vital microscopic study in the rabbit, Scand. J. Plastic Reconstruct. Surgery, 18, 261-268, 1984b.

Hashish, M. and Duplessis, M. P.: Theoretical and Experimental Investigation of Continuous Jet Penetration of Solids, J. Eng. Ind.T. ASME, 100, 88-94, 1978.

Hildebrand, T., Laib, A., Muller, R., Dequeker, J., and Ruegsegger, P.: Direct three-dimensional morphometric analysis of human cancellous bone: microstructural data from spine, femur, iliac crest, and calcaneus, J. Bone Mineral Res.: the official journal of the American Society for Bone and Mineral Research, 14, 1167-1174, doi:10.1359/jbmr.1999.14.7.1167, 1999.

Honl, M., Rentzsch, R., Lampe, F., Muller, V., Dierk, O., Hille, E., Louis, H., and Morlock, M.: Water jet cutting of bone and bone cement. A study of the possibilities and limitations of a new technique, Biomed Tech., 45, 222-227, 2000a.

Honl, M., Rentzsch, R., Muller, G., Brandt, C., Bluhm, A., Hille, E., Louis, H., and Morlock, M.: The use of water-jetting technology in prostheses revision surgery - First results of parameter studies on bone and bone Cement, J. Biomed. Mater. Res., 53, 781-790, 2000b.
Iyer, S., Weiss, C., and Mehta, A.: Effects of drill speed on heat production and the rate and quality of bone formation in dental implant osteotomies. Part II: Relationship between drill speed and healing, The Int. J. Prosthodon., 10, 536-540, 1997.

Matthews, L. S. and Hirsch, C.: Temperatures measured in human cortical bone when drilling, J. Bone Joint Surg. Am., 54, 297308, 1972.

Matthujak, A., Kasamnimitporn, C., Sittiwong, W., Pianthong, K., Takayama, K., and Milton, B. E.: Characteristics of impactdriven high-speed liquid jets in water, Shock Waves, 23, 105114, doi:10.1007/s00193-013-0431-1, 2013.

Mohamed, M. A. K.: Waterjet cutting up to $900 \mathrm{MPa}$, PhD, Universitat Hannover, 122 pp., 2004.

Nazarian, A., Araiza Arroyo, F. J., Rosso, C., Aran, S., and Snyder, B. D.: Tensile properties of rat femoral bone as functions of bone volume fraction, apparent density and volumetric bone mineral density, J. Biomechan., 44, 2482-2488, doi:10.1016/j.jbiomech.2011.06.016, 2011.

Orbanic, H. and Junkar, M.: An experimental study of drilling small and deep blind holes with an abrasive water jet, P. I. Mech. Eng. B.-J. Eng., 218, 503-508, 2004.

Pandey, R. K. and Panda, S.: Drilling of bone: A comprehensive review, J. Clinical Orthopaed. Trauma, 2013.

Schmolke, S., Pude, F., Kirsch, L., Honl, M., Schwieger, K., and Kromer, S.: Temperature measurements during abrasive water jet osteotomy, Biomed Tech., 49, 18-21, 2004.

Summers, D.: Waterjetting technology, 1st Ed., Taylor \& Francis, 1995.

Tikhomirov, R. A., Petukhov, E. N., Babanin, V. F., Starikov, I. D., and Kovalev, V. A.: High-pressure jetcutting, ASME Press, New York, 197 pp., 1992. 